\title{
SubJeTIVAÇÃo AUTÔNOMA, INDEPENDENTE E LETRADA: CONCEPÇÕES CONTRA-HEGEMÔNICAS SOBRE LINGUAGEM EM PRODUÇÕES ESCRITAS DE MULHERES NEGRAS
}

\author{
Michel Soares do CARMO*
}

RESUMO: Este artigo apresenta os resultados do estudo das ideias e dos argumentos sobre linguagem e seus derivados presentes em produções de mulheres autoras que se auto identificam como negras, a partir de uma perspectiva dos estudos culturais e pós-coloniais contemporâneos. Para isso, foi efetuado levantamento de produções escritas de mulheres autoidentificadas negras, disponíveis em acervos online, que contivessem as palavras-chave "língua", "linguagem", "escrever", "escrita", "discurso", "oral/oralidade" e "fala". Foram encontradas vinte produções. Para estas escritoras, a linguagem, principalmente a escrita, por ter sido a literatura o contexto temático da maioria dos textos encontrados, é marcada pelo corpo, isto é, pela raça e pelo gênero que guiam suas escritas, mesmo que para algumas isto não deva ser considerado o foco de sua escrita.

PALAVRAS-CHAVE: Corpo. Concepções de linguagem. Mulheres negras. Escritoras.

Introdução

Ao longo da história do Brasil, as mulheres negras têm sofrido constantes desvantagens nos campos sócio-político e econômico. Elas sofrem discriminações face à sua dupla condição: ser negra e ser mulher. (Regina M. Parente, 2008)

\footnotetext{
UFG - Universidade Federal de Goiás. Faculdade de Educação. Goiânia - GO - Brasil. 74605050 michel.linguista@gmail.com.
} 
A proposição da pesquisa de concepções de linguagem em produções escritas de mulheres negras surgiu no decorrer de uma etapa de pesquisa anterior ${ }^{1}$ (CARMO; PINTO, 2012). Na etapa anterior, foi bastante perceptível que há uma predominância da visibilidade da autoria masculina, mais precisamente de homens negros, em produções conhecidas como literatura marginal. Quando aparecem textos ou dados referentes a produções de mulheres negras, geralmente, elas recebem outro status ou pouco destaque ou são destacadas em posição diferente ao próprio movimento da periferia. Silva (2012) sobreleva que

desde muito cedo, as interdições à participação política das mulheres colocadas pelo patriarcado se impuseram. Às dificuldades materiais se somaram as lutas mais íntimas por construção de uma identidade não-subjugada, uma subjetividade de resistência aos imperativos do racismo e do machismo na vida cotidiana e nos espaços políticos de atuação. (SILVA, 2012, p. 01)

Estas interdições não cessam sua atuação político-social, mas, como se verá adiante, trazem conotações específicas para suas construções identitárias, lugares de participação e formas de resistência específicos e, por conseguinte, formas de vivenciar, conceber e avaliar linguagens situadas. Ainda pode-se acrescentar que, como pontua hooks² (1994b):

Há um conhecimento singular que surge do sofrimento, uma maneira de conhecer expressa frequentemente através do corpo, do que ele sabe, do que tem sido profundamente inscrito nele através da experiência. Esta complexidade da experiência raramente pode ser nomeada ou dada voz à distância. É um local privilegiado, mesmo não sendo o único ou mesmo sempre o mais importante local do que se pode saber. (hooks, 1994b, p. 91).

A autora faz tal afirmação a partir de sua experiência de feminista negra, defendendo que os corpos das mulheres, especialmente as mulheres negras, são locais contra-hegemônicos de resistência à opressão de gênero e à produção do conhecimento colonizada. Tendo em vista esta perspectiva, o que este grupo contra-

\footnotetext{
1 Ambas são etapas de pesquisa de Iniciação Científica ("Linguajamentos e contra-hegemonias sobre linguagem em produções escritas de literatura na periferia" 2011-2012, e "Linguajamentos e contrahegemonias sobre linguagem em produções escritas de mulheres negras" 2012-2013) desenvolvidas por Michel Soares do Carmo, integrante do projeto de pesquisa "Linguajamentos, corpos em crise e crítica do conhecimento: contra-hegemonias epistêmicas contemporâneas sobre linguagem" (2009-2013), coordenado por Joana Plaza Pinto. Agradeço muitíssimo a Joana Plaza Pinto por todas as discussões e orientações que geraram este artigo.

2 A escritora e intelectual bell hooks, nascida Gloria Watkins, assina seu nome sempre em caixas baixas e pede que assim seja feito em todas as citações de sua obra.
} 


\section{Subjetivação autônoma, independente e letrada: concepçôes contra-hegemônicas sobre linguagem em produçôes escritas de mulheres negras}

hegemônico identitário, mulheres negras escritoras, teria a dizer sobre linguagem? Onde estão as reflexões das mulheres negras escritoras sobre linguagem? Quais são as suas concepções? Como seus textos se articulam a suas práticas identitárias para produzir conhecimento sobre linguagem?

Como hooks (1995, p. 468) defende: "É o conceito ocidental sexista/racista de quem e o quê é um intelectual que elimina a possibilidade de nos lembrarmos de negras como representativas de vocação intelectual". Dessa forma, para ampliarmos nossas concepções de linguagem e seus conceitos correlatos a partir de pontos de vistas contra-hegeomônicos e assim mudarmos nossas possibilidades de pensar, fez-se necessário incluir a produção desse grupo não hegemônico, mulheres negras, na discussão sobre concepções de linguagem, língua, discurso e escrita. Para isso, este artigo se propõe a apresentar e discutir ideias e argumentos sobre linguagem e seus derivados presentes em produções de autoras que se autoidentificam como mulheres negras.

Assim, tem-se como objetivos 1) analisar as concepções de linguagem construídas em produções de mulheres autoidentificadas como negras, e 2) discutir o papel destas concepções de linguagem na contraposição às desigualdades a que este grupo identitário está exposto.

\section{Metodologia}

Para atingir os objetivos dispostos na seção anterior, seguiu-se a metodologia qualitativa de base documental. Foram estudadas produções escritas de participantes autodenominadas mulheres negras disponíveis em sites na web no ano de 2012. Essas produções são interpretadas no pano de fundo dos estudos culturais e póscoloniais contemporâneos (FROW; MORRIS, 2006; HALL, 2002; MAKONI; PENNYCOOK, 2007; MIGNOLO, 2003) e também com fundamentação nas discussões teóricas feitas por bell hooks (1984; 1994a; 1994b, 1995), pois sua obra relaciona questões relativas às mulheres negras com questões relativas à linguagem e à produção do conhecimento.

Os critérios de pesquisa delimitados foram os seguintes: busca por palavraschave referentes a conceitos de linguagem, sendo elas "língua", "linguagem", "escrever", "escrita", "discurso", "oral/oralidade" e "fala"; buscas em blogs/sites. O levantamento de nomes de autoras negras deu-se inicialmente no portal Literafro Literatura afro-brasileira (UFMG, 2012). Neste mesmo portal, iniciou-se a busca por páginas virtuais que possuíssem textos das autoras encontradas ou mesmo que fossem mantidos por elas. As autoras encontradas no portal Literafro foram pesquisadas no Portal Google por meio de seus nomes. Foram feitas também buscas 
neste mesmo portal a partir do marcador 'mulher(es) negra(s)' e com alternância dos seguintes termos: 'escritora(s)', 'acadêmica(s)', 'blogueira(s)' para se tentar encontrar outras escritoras além daquelas encontradas no portal Literafro. A partir destes mesmos marcadores, também foram efetuadas buscas no portal da Biblioteca Local. Somente textos em língua portuguesa foram selecionados.

Por fim, foram encontradas 20 produções: Dinha (2008), Evaristo (2003, [1990]2011, 2006, 2009a, 2009b), Natália (2012), Palmeira (2011a, 2011b), Salgueiro (2008), Silva (2008a, 2008b, 2008c, 2009, 2010a, 2010b), Silva (2010), Sobral (2011, 2012a, 2012b).

\section{Resultados e discussão}

Foram encontrados vinte textos de escritoras que se autodenominam como negras, os quais estão distribuídos entre oito autoras: Cidinha da Silva, Dinha, Cristiane Sobral, Lívia Natália, Conceição Evaristo, Francineide Santos Palmeira, Ana Rita Santiago da Silva, Maria Aparecida Andrade Salgueiro. Os textos das escritoras Cidinha da Silva, Cristiane Sobral e Conceição Evaristo foram todos encontrados em seus blogs individuais, mesmo que tenham sido publicados anteriormente em revistas ou sites (acadêmicos ou não). Os demais foram encontrados em sites acadêmicos, a partir da busca com as palavras-chave no portal Google.

Dos vinte textos encontrados, dezesseis concentraram suas concepções de linguagem em uma mesma área temática vinculada à escrita ou escrever, sendo eles: Entrevista à Revista Urbana (SILVA, 2008a); Barack Obama e Dinha entrevista (DINHA, 2008); Entrevista da Cidinha para a Ana (SILVA, 2008b); Entrevista da Cidinha para Luana (SILVA, 2008c); Notas sobre o processo de criação literária, ao poeta Rique Aleixo (SILVA, 2009); Entrevista da Cidinha para Literatura Subversiva (Silva, 2010a); Entrevista da Cidinha para Película Negra (SILVA, 2010b); Dos desejos (NATÁLIA, 2012); Representações das mulheres negras sob a ótica feminina nos Cadernos Negros (PALMEIRA, 2011a); Eu não sei cantar - Entrevista à Raça (EVARISTO, 2006); Diálogos com a cultura afrobrasileira (SALGUEIRO, 2008); A literatura de escritoras negras: uma voz (des) silenciadora e emancipatória (SILVA, 2010); Dos sorrisos, dos silêncios e das falas (EVARISTO, 2009a); Literatura Negra: uma poética de Afro-brasilidade (EVARISTO, 2009b); Assenhorando-se do poder da palavra: Escritoras afrobrasileiras e auto-representações (PALMEIRA, 2011b); Gênero e Etnia: uma escre (vivência) de dupla face (EVARISTO, 2003).

Os outros quatro não se vinculam às palavras-chave escrever e escrita diretamente: 20 de Novembro (SOBRAL, 2011); Erro de português (SOBRAL, 
Subjetivação autônoma, independente e letrada: concepçôes contra-hegemônicas sobre linguagem em produçôes escritas de mulheres negras

2012a); Provocações (SOBRAL, 2012b); Vozes-Mulheres (EVARISTO, [1990] 2011). Como seria esperado, estes também são os únicos textos que não têm a literatura ou fazer literário como tema principal, refletindo sobre o uso da língua e/ou fala em geral. De todo modo, estes também apresentam uma perspectiva temática, ao conceber linguagem, que está em consonância com o grafocentrismo (SIGNORINI, 2008).

Dois aspectos contextuais são significativos e adquirem relevância se comparados com os dados contextuais do estudo anterior, Linguajamentos e contrahegemonias sobre linguagem em produções escritas de literatura na periferia. $\mathrm{O}$ primeiro é o fato de as publicações se concentrarem em blogs individuais, apesar de também serem blogs com temática, principalmente literária, como aqueles de literatura marginal, os quais, no entanto, apresentavam um tom de coletividade em relação à autoria (mesmo que predominantemente masculina) não encontrado nos blogs das autoras. O segundo aspecto é o de todas as autoras estarem vinculadas à academia, direta ou indiretamente, enquanto que entre as produções de literatura marginal encontradas no estudo anterior, também conduzido em ambiente online, isso não ocorreu.

Há de se ressaltar que o vínculo entre as concepções de linguagem e a literatura é estreito, pois elas pensam a linguagem de um lugar/contexto específico que ocorre a partir do entrelaçamento e articulação de várias categorias (ANZALDÚA, 2009; CALDWELL, 2000; PISCITELLI, 2008). Esta intersecção de categorias (mulheres, negras, escritoras, acadêmicas) produz uma forma de lidar com a linguagem e pensá-la muito situada, o que também transparece na maneira pela qual as escritoras associam linguagem, literatura e corpo num processo de construção da identidade.

Não que esta forma de pensar a linguagem não tenha pontos em comum com outros grupos contra-hegemônicos. Certamente, há. O principal deles é, assim como no caso dos escritores de literatura marginal, o reconhecimento de que a língua tem sido usada como um mecanismo do poder e de uma tradição eurocêntrica que regula o dizer (MIGNOLO, 2003). A partir dessa consciência, as autoras estudadas fizeram da escrita um instrumento de resistência ao discurso que as inferioriza e no qual o corpo e a linguagem são elementos que possibilitam a construção de uma identidade própria, local e positiva. É nesse sentido que Dinha (2008), na entrevista Barack Obama e Dinha, ao se referir à escrita da periferia, expõe:

Nem o que vem da periferia e nem o que é alheio a ela são simplesmente positivos ou negativos. O Movimento Hip Hop, por exemplo, vem narrando, oralmente, através do Rap, várias nuances da periferia. Isso é bastante positivo pra mim que nunca havia lido/visto/ouvido minha história, da minha família e 
dos meus vizinhos, a não ser a partir de olhares de fora, estrangeiros. Entretanto, o Movimento é mesmo machista e sexista, assim como a grande maioria das pessoas da nossa sociedade também o são. Isso não tira sua importância. [...]. Quero reforçar que apesar de escrever PARA todas as pessoas, escrevo, principalmente, POR mim. E eu sou mais que eu mesma. Sou meus irmãos, minha comunidade. (DINHA, 2008, n.p.).

Para essas escritoras, a linguagem, principalmente a escrita por ter sido a literatura o contexto temático da maioria dos textos, é marcada pelo corpo, isto é, pela raça e pelo gênero que guiam suas escritas, como delineia Cidinha da Silva (2010b) em Entrevista da Cidinha para Película Negra:

Eu sou uma mulher negra aqui e em qualquer lugar do mundo. Mais do que uma escritora negra sou uma negra escritora, tal como seria uma negra médica, gari, cozinheira, professora universitária. Ser negra é nome. É substantivo, principalmente em sociedades racistas e racializadas como a brasileira. (SILVA, 2010b, n.p.).

Cidinha da Silva (2008a, 2008b, 2008c, 2009, 2010a, 2010b), em todos os seus textos encontrados que refletem sobre linguagem, coloca que é inevitável fugir da experiência de uma escrita marcada pela experiência corporal (do lugar do qual se escreve), mas que isso não deve ser a essência daquilo que se propõe como fazer literário: "Sou negra, isto posto, intento produzir uma manufatura (ops, literatura) em que as pessoas negras possam também se reconhecer, sem que para isso eu tenha de produzir um discurso direto e, em muitos casos, sem literariedade" (SILVA, 2008c, n.p.). Dessa forma, ela propõe que a literatura produzida por elas não deve ser reconhecida apenas como ou principalmente por sua militância, seu caráter político.

Por outro lado, também aparece a defesa de uma experiência com a linguagem que se dê de forma mais militante, que afirme o lugar de onde se escreve, como estabelece Conceição Evaristo (2009b) em Literatura Negra: uma poética de Afrobrasilidade:

Estou de pleno acordo, mas insisto na constatação óbvia de que o texto, com o seu ponto de vista, não é fruto de uma geração espontânea. Ele tem uma autoria, um sujeito, homem ou mulher, que com uma "subjetividade" própria vai construindo a sua escrita, vai "inventando, criando" o ponto de vista do texto. Em síntese, quando escrevo, quando invento, quando crio a minha ficção, não me desvencilho de um "corpo-mulher-negra em vivência" e que por ser esse "o meu corpo, e não outro", vivi e vivo experiências que um corpo não negro, não mulher, jamais 


\section{Subjetivação autônoma, independente e letrada: concepçôes contra-hegemônicas}

sobre linguagem em produçôes escritas de mulheres negras

experimenta. As experiências dos homens negros se assemelham muitíssimo às minhas, em muitas situações estão par a par, porém há um instante profundo, perceptível só para nós, negras e mulheres, para o qual nossos companheiros não atinam. Do mesmo modo, penso a nossa condição de mulheres negras em relação às mulheres brancas. Sim, há uma condição que nos une, a de gênero. Há, entretanto, uma outra condição para ambas, o pertencimento racial, que coloca as mulheres brancas em um lugar de superioridade - às vezes, só simbolicamente, reconheço - frente às outras mulheres, não brancas. E desse lugar, muitas vezes, a mulher branca pode e pode se transformar em opressora, tanto quanto o homem branco. (EVARISTO 2009b, p. 18).

Cristiane Sobral (2011, 2012a, 2012b) é a única autora estudada que não define linguagem vinculando diretamente à literatura e sim à língua em sentido mais amplo, apesar de haver marcações associadas a escrita. Todos os seus textos apresentam também o corpo como o lugar de onde se parte para se conceber a língua(gem), a qual se aproxima da proposta de Conceição Evaristo, como no trecho: "É preciso estudar os dicionários para criar outras línguas e perceber que ainda podemos desdobrar, articular a nossa língua misturando bantu com iorubá, [...] Pela criação de uma nova gramática repleta de negrume, para que possamos recitar em bom negrês, que chegará a nossa vez" (SOBRAL, 2012a, n.p.).

Diferentemente do que ocorreu nas concepções de linguagem dos escritores de literatura marginal, não houve uma ligação estreita ou mesmo uma associação entre oralidade e escrita, nas concepções das escritoras negras encontradas. O que se justifica pelo lugar de onde estas escritoras falam, que não é uma imaginada periferia iletrada, mas sim de um ambiente marcadamente letrado, muitas vezes acadêmico e outras vezes não acadêmico, no qual a forma de se conceber a escrita não está, pelo menos a priori, ligada à oralidade. Por outro lado, outras formas de identificação as unem: suas experiências como mulheres negras, uma experiência com a linguagem marcada pelo corpo. Ademais, ressalta-se que a construção de suas identidades, textos e concepções são marcadas historicamente por temáticas culturais associadas a culturas africanas e afro-brasileiras, as quais são indiciadas em diversos trechos sejam por palavras específicas (bantu com ioruba, gegê, nagô), figuras de linguagem ou por afirmações específicas.

Em consonância com o que têm pesquisado Dalcastagnè (2007) e argumentado Anzaldúa (2009) sobre se buscar uma ruptura com o silêncio e se iniciar um movimento de autorrepresentação literária, Conceição Evaristo (2003, p. 06) explicita como esta dupla condição de negra e mulher, marcadas corporalmente, traz implicações quando "colocada a questão da identidade e diferença no interior da linguagem, isto é, como atos de criação linguística, [...] apresenta um discurso que 
se prima em proclamar, em instituir uma diferença negativa para a mulher negra" e quando adicionada uma outra categoria intersectiva que é o ambiente específico de atuação desta escritora (e que pode se estender às demais aqui estudadas), basicamente letrado, traz uma forma bastante especifica de se pensar sua escrita literária:

Assenhoreando-se "da pena", objeto representativo do poder falo-cêntrico branco, as escritoras negras buscam inscrever no corpus literário brasileiro imagens de uma auto-representação. Surge a fala de um corpo que não é apenas descrito, mas antes de tudo vivido. A escre (vivência) das mulheres negras explicita as aventuras e as desventuras de quem conhece uma dupla condição, que a sociedade teima em querer inferiorizada, mulher e negra". (PALMEIRA, 2011b, p. 8)

As concepções de linguagem apresentadas estavam circundadas para mostrar que a escrita da mulher negra é marcada por uma desvalorização e/ou subestimação, sendo isto ainda uma herança patriarcal, pois, como expõe Conceição Evaristo (2006, n.p.) em Eu não sei cantar, "se você não está na mídia e ainda é negro e mulher, a situação se complica mais, porque espera-se que a mulher negra seja capaz de desempenhar determinadas funções, como cozinhar muito bem, dançar, cantar - mas não escrever" e, também Cidinha da Silva (2010a, n.p.) em Entrevista da Cidinha para Literatura Subversiva, "nossas particularidades humanas negras não geram interesse editorial, não são tratadas como o particular que fala do humano e é, portanto, universal". Estas associações entre lugar social, desvalorização e linguagem indiciam que concepções de linguagem são afetadas por suas jornadas e fazem com que se posicionem de modo a criar resistências específicas por meio articulações criativas entre suas marcas corporais e espaços (concretos ou simbólicos) sociais que se tem à disposição.

De todo modo, das articulações que marcam as formas como essas escritoras negras concebem linguagem, os processos de marcação do corpo e suas relações com a literatura e o ambiente acadêmico, surgem muitas possibilidades de se pensar linguagem que são situadas e, de modo explícito, marcadas pela experiência. Ao contrário do cenário acadêmico-literário que, muitas vezes, se vale de discursos sobre linguagem que buscam uma univocidade e totalização conceitual na qual não se marca o lugar de onde se fala e, menos ainda, como ele afeta nossas visões e concepções. Assim, o movimento dessas escritoras e suas reflexões sobre linguagem apontam para o que Gomes argumenta em 2008 ao discutir a literatura afrobrasileira:

A literatura afro-brasileira subtrai do discurso dominante as presumíveis univocidades na medida em que a sua escrita rasura e subverte a construção das 
narrativas da história oficial, investindo em outras possibilidades de elaboração. É uma escrita que acrescenta, nega, questiona, incomoda (DHYTTA, 1995, p. 122).

Estas possiblidades de elaboração que subvertem narrativas oficiais mostram que estas mulheres se valem do que têm acesso simbolicamente para construir resistências situadas acerca de linguagem e de representatividade social. É isto que é sumarizado no diagrama a seguir. Na Figura 1, o maior círculo, Mulheres negras, representa as concepções dessas mulheres e o segundo maior, Literatura da periferia, representa as concepções deste grupo de literatura periférica, majoritariamente composto de homens negros. Como é possível perceber, não há uma intersecção direta entre as concepções dos dois grupos apesar de elas terem marcadores sociais e/ou experiências em comum que aparecem em ambos os conjuntos: as experiências com a escrita literária; a raça negra que se vincula ao movimento negro; e gênero. No entanto, como já apontado nas discussões, a forma como as articulações entre esses marcadores e experiências ocorrem é alterada quando situamos o contexto de produção destes grupos, produzindo tanto apagamentos quanto visibilizações.

Figura 1 - Diagrama das intersecções apresentadas

pelas concepções de linguagem identificadas

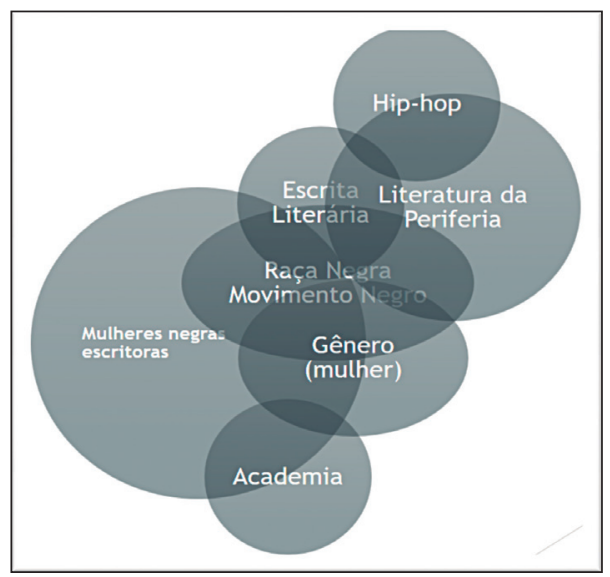

Fonte: Elaborado pelo autor

Neste caso, por exemplo, como podemos ver na intersecção do círculo que marca gênero, ele é um marcador apagado nas concepções do grupo de Literatura da periferia enquanto, por outro lado, é ressaltado nas concepções destas mulheres negras, o que indica um determinado tipo de subjetivação que reflete bastante a importância da sua identidade/experiências de gênero em suas concepções de 
linguagem, mais especificamente a escrita e seu vínculo à academia. Quando mencionamos este apagamento, não pretendemos dizer que no movimento de literatura periférica não haja mulheres, mas sim que elas pouco aparecem e que questões vinculadas a seu corpo são, justamente por isso, apagadas, não discutidas.

Dois exemplos de visibilizações, no sentido daquilo que toma destaque ou importância nestas concepções, por fazer parte das estratégias/práticas destes grupos, que aparecem na análise comparativa são: as concepções destas mulheres negras são altamente impactadas por seu pertencimento à academia, por falarem/escreverem a partir de um lugar de fala de prestígio letrado; e as concepções de escritores de literatura marginal são altamente articuladas com o pertencimento deste grupo a práticas orais, como o Hip-Hop, pois é deste local que eles escrevem/falam. Porém, tais visibilizações não se intersectam nas concepções analisadas, como é possível ver no diagrama nos círculos academia e Hip-Hop, sendo a academia um marcador que não aparece como relevante nas concepções dos escritores de literatura da periferia e o Hip-Hop, de mesmo modo, não é tratado como um lugar de fala importante para estas escritoras negras.

Por outro lado, o círculo raça negra - Movimento negro está presente em ambos e é elemento central que se articula com os outros marcadores de diferença presentes nas concepções de cada grupo. Isto é, para as escritoras negras, raça se articula de maneira sumária com gênero para marcar como elas experienciam seu corpo e refletem sobre isso linguisticamente e, ainda, esta articulação se vincula a um terceiro marcador de diferença, a academia. No entanto, esse último está muito mais vinculado a como estas mulheres atuam no mundo e buscam ambientes de resistência nos quais sua voz tenha mais plenitude, autonomia e independência, e que possam contrapor-se às desigualdades a que estão sujeitas.

\section{Considerações finais}

É peculiar às produções aqui estudadas que sua circulação se dê em contextos individualizados (colunas em blogs e entrevistas etc.) e mais acadêmicos, em que as autoras, para ganhar espaço legitimado (EVARISTO, 2003; hooks, 1984, 1995), investem na construção de uma subjetivação autônoma, independente e letrada como ganho e rebeldia para o lugar discursivo da mulher negra, como foi possível ver no diagrama (Figura 1).

Portanto, as produções encontradas apresentam concepções de linguagem que são comuns a vários grupos minoritarizados e contra-hegemônicos (OLIVEIRA \& PINTO, 2011; PINTO \& BADAN, 2012), no caso a ideia da linguagem como resistência. Porém, há nuances que são específicas para o grupo de mulheres negras. 
Subjetivação autônoma, independente e letrada: concepçôes contra-hegemônicas sobre linguagem em produçôes escritas de mulheres negras

Essas produções defendem a busca de elementos identitários e de resistência por meio das práticas linguísticas que se vinculam ao campo da literatura e se baseiam em suas experiências corporais. Assim, as concepções de linguagem identificadas vão ao encontro do que é teorizado por autoras e autores que propõem a rearticulação das práticas linguísticas e a marcação "[d] o lugar geopolítico [que] compõe o contexto hegemônico ou subalterno de uma língua em relação às demais" (PINTO, 2011, p. 70).

\section{AUTONOMOUS, INDEPENDENT AND LETTERED SUBJECTIVATION: CONTRA-HEGEMONIC LANGUAGE CONCEPTIONS IN WRITTEN PRODUCTIONS OF BLACK WOMEN WRITERS}

ABSTRACT: This article analyses ideas and arguments about language and its derivatives in written productions of self-identified black women writers, from the viewpoint of contemporary cultural and post-colonial studies. For that, we mapped the written productions of self-identified black women writers available online, selected through the key-words "language", "to write", "written", "discourse", "oral/ity", and "speech". Twenty productions were found as a result. For these authors, language - particularly the written word considering literature is the main thematic context of the texts that were found - is marked by the body, that is, by the race and gender which guide their writings. However, to some of them, this should not be considered as the main focus of their writings.

KEYWORDS: Body. Language conceptions. Black women. Writers.

\section{REFERÊNCIAS}

ANZALDÚA, G. Como domar uma língua selvagem. Trad.: Joana Plaza Pinto e Karla Cristina dos Santos. Cadernos de Letras da UFF, Niterói, n. 39, p. 297-309, 2009.

CALDWELL, Kia L. Fronteiras da diferença: raça e mulher no Brasil. Revista Estudos Feministas, Rio de Janeiro, v., out, p. 203-216, 2000.

CARMO, Michel S. do; PINTO, Joana P. Linguajamentos e contra-hegemonias sobre linguagem em produções escritas de literatura na periferia. Anais do Congresso de Pesquisa, Ensino e Extensão- CONPEEX, Goiânia, UFG, 2012, p. 3613-3622.

DALCASTAGNÈ, Regina. A auto-representação de grupos marginalizados: tensões e estratégias na narrativa contemporânea. Letras de Hoje, Porto Alegre, v. 42, n. 4, p. 18-31, dezembro 2007. 
DINHA. Barack Obama e Dinha. 2008. Disponível em: < http://cidinhadasilva.blogspot. com/2008/03/barack-obama-e-dinha.html>. Acesso em: 11 abr. 2013.

DHYTTA, Lourdes [Lourdes Benedita da Silva]. Perdas nas mãos. In: ALVES, Miriam Aparecida; DURHAM, Carolyn Richarson (Orgs.). Enfim... Nós/Finally... Us: Escritoras negras brasileiras contemporâneas/Contemporary black Brazilian women writers. Colorado Springs: Three Continents Press, 1995.

EVARISTO, Conceição. Eu não sei cantar - Entrevista à Raça. In: Revista Raça. 2006. Disponível em: <http://nossaescrevivencia.blogspot.com.br.> Acesso em 13 abr. 2013.

. Vozes-Mulheres. In: PALMEIRA, Francineide Santos. Representações de Mulheres Negras Sob a Ótica Feminina nos Cadernos Negros. Revista da ABPN. vol. 1, n. 3, nov. 2010/fev. 2011. Disponível em: <http://www.abpn.org.br/Revista/index.php/edicoes/article/ viewArticle/71.> Acesso em: 17 fev. 2013.

. Dos sorrisos, dos silêncios e das falas. In: SCHNEIDER, Liane e MACHADO, Charliton (orgs.). Mulheres no Brasil - Resistência, lutas e conquistas. João Pessoa, Editora Universitária, UFPB, 2009a. Disponível em: $<$ http://nossaescrevivencia.blogspot. com.br/2012/08/dos-sorrisos-dos-silencios-e-das-falas.html.> Acesso em: 13 abr. 2013.

. Literatura Negra: uma poética de Afro-brasilidade. SCRIPTA, Belo Horizonte, v. 13, n. 25, p. 17-31, $2^{\circ}$ sem, 2009b. Disponível em: <http://nossaescrevivencia.blogspot. com.br.> Acesso em: 13 abr. 2013.

. Gênero e Etnia: uma escre(vivência) de dupla face. In: Seminário Nacional X Mulher e Literatura - I Seminário Internacional Mulher e Literatura/ UFPB, 2003. Disponível em: <https://b5af303c-a-62cb3a1a-s-sites.googlegroups.com/site/nossaescre vivencia/ensaios/SESS\%2B\%C3\%A2O \%20ESCREVIV\%2B\%C3\%A8NCIA\%20Ensaio \%201.pdf?attachauth=ANoY7coYpT0TDFVa0AhGKXRebW6s4yZBRpuy0k1gWNnFim 5oaFfobR_cCbO5Xf66Rwd4jgB1R1GYqOfUilSpvL1K7DJTD66sskWzLfwwbQIjKIP7Sk fgY4WhYvofrtozzD5gWyXpy0_pANVkdUwCfu3xKN-mpXJJIRI3aBJwBaJJ0aO9XSfHP MRbKLQh9eqi83WSM-LAuBWIrglxmh6e4_mimGzFEUTcU7k4jwPyyvzbPUMIvXYKr er60RqXJxEriF9ui7aDwZp52R78PWM7QyoncuHg32stdg\%3D\%3D\&attredirects=0. Acesso em: 07 ago. 2013.

FROW, John; MORRIS, Meaghan. Estudos culturais. In: DENZIN, Norman K. (ed.). O planejamento da pesquisa qualitativa. 2. ed. Trad.: Sandra Regina Netz. Porto Alegre: Artmed, 2006. Cap. 11: p. 315-343.

HALL, Stuart. A identidade cultural na pós-modernidade. 7. ed. Trad.: Tomaz Tadeu da Silva e Guacira Lopes Louro. Rio de Janeiro: DP\&A, 2002.

hooks, bell. Linguagem: ensinar novas paisagens/novas linguagens. Revista Estudos Feministas, Florianópolis, v. 16, n. 3, p. 857-864, dez. 2008. 
Subjetivação autônoma, independente e letrada: concepçōes contra-hegemônicas sobre linguagem em produçôes escritas de mulheres negras

. Intelectuais negras. Revista de Estudos Feministas, Rio de Janeiro, N. 3, $2^{\circ}$ sem./1995, p. 464-478.

. Outlaw culture: resisting representations. New York: Routledge, 1994a.

. Teaching to transgress: education as the practice of freedom. New York: Routledge, 1994b.

. Feminist theory from margin to center. Boston: South End Press, 1984.

MAKONI, Sinfree; PENNYCOOK, Alastair. Disinventing and reconstituting languages. In: . Disinventing and reconstituting languages. Clevedon: Multilingual Matters, 2007.

MIGNOLO, Walter D. Histórias locais / Projetos globais: colonialidade, saberes subalternos e pensamento liminar. Trad.: Solange Ribeiro de Oliveira. Belo Horizonte: Editora da UFMG, 2003.

NATÁLIA, Lívia. Dos desejos. 2012. Disponível em: <outrasaguas.blogspot.com. br/2012/02-do-desejo.html.> Acesso em: 04 fev. 2013.

OLIVEIRA, Elismennia A.; PINTO, Joana Plaza. Linguajamentos e contra-hegemonias epistêmicas sobre linguagem em produções escritas indígenas. Linguagem em (Dis)curso, v. 11, n. 2, p. 311-335, 2011.

PALMEIRA, Francineide Santos. Representações de Mulheres Negras Sob a Ótica Feminina nos Cadernos Negros. Revista da ABPN. V. 1, N. 3, nov. 2010/fev. 2011a. Disponível em: $<$ http://www.abpn.org.br/Revista/index.php/edicoes/article/viewArticle/71.> Acesso em: 17 fev. 2013.

. Assenhoreando-se do poder da palavra: Escritoras afro-brasileiras e autorepresentações. In: Anais do XIV Seminário Nacional Mulher e Literatura. Brasília: Universidade de Brasília, 2011b. Disponível em: <http://www.telunb.com.br/mulhereliteratura/ anais/wp-content/uploads/2012/01/francineide_santos.pdf.> Acesso em: 17 fev. 2013.

PARENTE, Regina Marques. O silêncio da cor. In: Seminário Internacional Fazendo Gênero 8, 2008, Florianópolis. Corpo, violência e poder, 2008. v. 1. p. 1-5.

PINTO, Joana Plaza. Da língua-objeto à práxis linguística: desarticulações e rearticulações contra hegemônicas. Linguagem em Foco, v. 2, p. 69-83, 2011.

PINTO, Joana Plaza; BADAN, Suzana C. Feminismo e as identidades no cerne dos princípios de pesquisa. Calidoscópio (UNISINOS), v. 10, n. 2, p. 133-139, 2012.

PISCITELLI, Adriana. Interseccionalidades, categorias de articulação e experiências de migrantes brasileiras. Sociedade e Cultura, v.11, n.2, jul/dez. 2008. p. 263-274. Disponível em $<$ http://www.revistas.ufg.br/index.php/fchf/article/viewFile/5247/4295.> Acesso em: 21 jul. 2013. 
SALGUEIRO, Maria Aparecida Andrade. Diálogos com a Cultura Afro-Brasileira - Varsóvia, Polônia. In: Colóquio dos 30 Anos da Secção Luso-Brasileira do Instituto de Estudos Ibéricos e Ibero-Americanos da Universidade de Varsóvia, 2008. Varsóvia - Polônia. Actas do Colóquio dos 30 Anos da Secção Luso-Brasileira do Instituto de Estudos Ibéricos e Ibero-Americanos da Universidade de Varsóvia, 2008. Disponível em: <http://iberystyka-uw. home.pl/pdf/Dialogos-Lusofonia/Coloquio_ISIiI-UW_28_SALGUEIRO-Maria-Aparecida_ Dialogos-com-a-cultura-afro-brasileira.pdf.> Acesso em: 04 mar. 2013.

SIGNORINI, Inês. Metapragmáticas da Língua em uso: Unidades e níveis de análise. In: BLOMMAERT, J. (org.) Contexto é/como crítica. Situar a linguagem. São Paulo: Parábola, 2008, p. 117-148.

SILVA, Ana Rita Santiago da. A literatura de escritoras negras: uma voz (des) silenciadora e emancipatória. Interdisciplinar. v. 10, jan-jun de 2010, p. 175-188. Disponível em: $<$ http://200.17.141.110/periodicos/interdisciplinar/revistas/ARQ_INTER_11/INTER11_15.pdf.> Acesso em: 04 mar. 2013.

SILVA, Carmen. Feminismo e pensamento pós-colonial. Website SOS Corpo. 2012. Disponível em: <http://www.soscorpo.org.br/images/PDFs_do_blog/Feminismo_e_PosColonialidade_CarmenSilvaSOSCorpo22JULHO12.pdf.> Acesso em: 21 jul. 2013.

SILVA, cidinha da. Entrevista da Cidinha para Literatura Subversiva. 2010a. Disponível em: <cidinhadasilva.blogspot.com.br/2010/03/entrevista-de-cidinha-da-silva-para-o.html.> Acesso em: 11 abr. 2013.

. Entrevista da Cidinha para Película Negra. 2010b. Disponível em: <cidinhada silva.blogspot.com.br/2010/06/cidinha-da-silva-em-entrevista-no.html.> Acesso em: 11 abr. 2013.

. Notas sobre um processo de criação literária, ao poeta Rique Aleixo. 2009. Disponível em: <cidinhadasilva.blogspot.com.br/2009/12/notas-sobre-um-processo-decriacao.html.> Acesso em: 11 abr. 2013.

. Entrevista à Revista Urbana. 2008a. Disponível em: <cidinhadasilva.blogspot. com.br/2008/03/cidinha-na-revista-urbana.html.> Acesso em: 11 abr. 2013.

. Entrevista da Cidinha. 2008b. Disponível em: cidinhadasilva.blogspot.com. br/2008/08/entrevista.html. Acessado em: 11 de abril de 2013.

. Entrevista da Cidinha para professora Luana. 2008c. Disponível em: cidinhada silva.blogspot.com.br/2008/12/entrevista-para-professora-luana.html. Acessado em: $11 \mathrm{de}$ abril de 2013.

SOBRAL, Cristiane. Erro de português. 2012a. Disponível em: <cristianesobral.blogspot. com.br-2012/06/erro-de-portugues-poesia.html. Acessado em: 02 de março de 2013. 
Subjetivação autônoma, independente e letrada: concepçôes contra-hegemônicas sobre linguagem em produçôes escritas de mulheres negras

Provocações. 2012b. Disponível em: <cristianesobral.blogspot.com.br-2012/08/ provocacoes.html.> Acesso em: 02 mar. 2013.

20 de novembro. 2011. Disponível em: cristianesobral.blogspot.com.br-2011/03/20de-novembro.html. Acesso em: 02 mar. 2013.

UFMG. Portal LITERAFRO. Disponível em: <http://www.letras.ufmg.br/literafro/.> . Múltiplos acessos em 2012.

Recebido em 10/02/2018.

Aprovado em 22/04/2018. 
